Artigos

Volume 7 - $2017 \mid$ n. 9

\title{
O Financiamento das IEEs Brasileiras frente ao Processo de Expansão da Educação Superior: um estudo da Universidade do Estado do Pará (2003-2010)
}

\author{
Giselle dos Santos Ribeiro \\ Tayanne de Fátima Almeida Tabosa dos Reis \\ Valeria Silva de Moraes Novais \\ Ana Paula Batista da Silva Brito \\ Universidade Federal do Pará (UFPA), Belém/PA - Brasil \\ Emerson Duarte Monte \\ Universidade do Estado do Pará (UEPA), Belém/PA - Brasil
}

\section{Resumo}

O artigo apresenta um estudo acerca do financiamento da educação superior brasileira sob a racionalidade da atual política expansionista, relacionando-a com as mudanças decorrentes da Reforma do Estado de 1995. O objetivo foi analisar como o financiamento das instituições estaduais acompanha seus processos de expansão e como isso se expressa na Universidade do Estado do Pará, no período de 2003 a 2010. Para tanto, foram utilizados dados dos Balanços Gerais do Estado do Pará, do Instituto Brasileiro de Geografia e Estatísticas e do Instituto Nacional de Estudos e Pesquisas Educacionais Anísio Teixeira, adotando, portanto, uma abordagem quanti-qualitativa. Os dados apontam que o PIB estadual cresceu no período, bem como a receita corrente líquida, porém, apesar de na aparência ter-se ampliado o repasse de recursos para a universidade, uma parcela ínfima corresponde a investimentos reais na expansão ocorrida. Reforça-se, por fim, o indicativo da ausência de uma política de financiamento.

Palavras-chave: Financiamento. Expansão. Universidades Estaduais. UEPA.

\section{Funding of Brazilian Public Universities in the Process of Higher \\ Education Expansion: a study of The State University of Pará (2003-2010)}

\section{Abstract}

This essay presents a study about Brazil's higher education funding in view of the rationality of its current expansionary policy, relating it to the consequences of the state reform, started in 1995. It aims to analyze how institutional funding by the state follows this expansion process, through the investments transferred to the University of the Pará State (UEPA), from 2003 to 2010. It uses data from the 'General Balance the State of Pará', the Brazilian Institute of Geography and Statistics and the National Institute of Educational Studies Anísio Teixeira, in a quantitative and qualitative approach. Data show that the state's GDP increased in the period and so did the net current revenue during the period. However, even if seems that the university funds increased, only a minimum has effectively been invested in its expansion. It shows that UEPA suffers with an inequality of investments and that indicates a lack of a funding policy in that state.

Keywords: Funding. Expansion. State Universities. UEPA. 
O Financiamento das IEEs Brasileiras frente ao Processo de Expansão da Educação Superior

\section{Introdução}

Este artigo compõe os estudos sobre o financiamento da educação superior desenvolvidos no Grupo de Estudos e Pesquisas sobre Educação Superior (GEPES) da Universidade Federal do Pará (UFPA). O texto apresenta parte da pesquisa relacionada ao financiamento da educação superior brasileira sob a racionalidade da política expansionista dos últimos anos e relaciona-o com as mudanças subsequentes à Reforma do Estado da década de 1990. Assim, discute-se de que forma a educação superior foi afetada pelas mudanças políticas e econômicas, principalmente nas instituições estaduais de ensino superior.

O objetivo foi analisar como o financiamento das instituições estaduais acompanha seus processos de expansão e como isso se expressa na Universidade do Estado do Pará, no período de 2003 a 2010. O período corresponde aos governos de Simão Jatene (2003-2006), do Partido da Social Democracia Brasileira (PSDB), e de Ana Júlia Carepa (2007-2010), do Partido dos Trabalhadores (PT). Por serem partidos ideologicamente diferentes, cabe indagar em que medida o tratamento à educação superior foi diferenciado.

Para isso, adota-se uma abordagem quanti-qualitativa com o levantamento bibliográfico acerca da temática investigada, bem como de coleta e sistematização de dados em sites oficiais - Instituto Nacional de Estudos e Pesquisas Educacionais Anísio Teixeira (INEP) e Instituto Brasileiro de Geografia e Estatística (IBGE) - e em documentos oficiais do governo do estado do Pará, os Balanços Gerais do Estado (BGE).

Inicialmente, discorre-se sobre a Reforma do Estado e suas implicações para o financiamento da educação superior. Em seguida, discute-se a expansão da educação superior na Universidade do Estado do Pará (UEPA). Nas Considerações Finais, ponderamse as dificuldades de expandir as matrículas sem que haja ampliação dos recursos.

\section{A Reforma do Estado: sustentáculos para as reformas educacionais}

O reordenamento do mundo do trabalho, iniciado na década de 1970 como resposta à grande crise econômica mundial, combinou altas taxas de inflação e baixos índices de crescimento. Esse fato possibilitou que as ideias neoliberais ganhassem espaço e tornassem a regulação por meio do mercado (a não intervenção estatal na economia, a seletividade dos gastos públicos e a paulatina ampliação de recursos em políticas sociais compensatórias) o eixo norteador da economia mundial (MANCEBO; MAUES; CHAVES, 2006).

Tais alterações de ordem política e econômica, demandadas pela atual etapa de desenvolvimento capitalista, visavam financiar a formação do capital humano e eleger a competitividade internacional das empresas, utilizando ações cujo alvo central era implementar amplas mudanças na organização e na administração do Estado, submetendoo a adotar a lógica de mercado.

Comumente se diz que, para os neoliberais, a principal saída era a diminuição do Estado. Porém, para Anderson (1995, p. 11), a perspectiva era de:

[...] manter um Estado forte, sim, em sua capacidade de romper o poder dos sindicatos e no controle do dinheiro, mas parco em todos os gastos sociais e nas intervenções econômicas. A estabilidade monetária deveria ser a meta suprema de qualquer governo. Para isso, seria necessária uma disciplina orçamentária, com a contenção dos gastos 
O Financiamento das IEEs Brasileiras frente ao Processo de Expansão da Educação Superior

com bem-estar, e a restauração da taxa 'natural' de desemprego, ou seja, a criação de um exército reserva de trabalho, para quebrar os sindicatos.

A diminuição do Estado correspondia ao processo de privatização que se pregava e que culminava com a desresponsabilização do Estado pelo desenvolvimento de alguns setores para dar atenção ao fortalecimento e à centralização sobre o controle do dinheiro e a reação dos sindicatos às condições adversas ao trabalho, criadas com a adoção da nova doutrina.

Tratava-se, agora, de fazer com que o Estado adotasse características administrativas e gerenciais nos setores sob a sua direção. Na educação, em particular, essa reforma se traduziu em um acompanhamento da evolução do mercado globalizado: "[...] o processo resultante de uma nova fase de reestruturação capitalista é marcado por políticas de centralização, de diferenciação e de diversificação institucional e, especialmente, de privatização da esfera pública" (DOURADO, 2002, p. 235).

Em virtude desse reordenamento do mundo do trabalho, Mancebo (2010) afirma que o Estado brasileiro reformado utilizou-se de medidas jurídico-políticas para viabilizar, em maior ou menor escala, as reformas no sistema educacional. A privatização, a racionalização de recursos, a adoção de avaliações de matriz gerencial, o modelo de gestão flexibilizada para o corte de custos e as reformas curriculares foram medidas que tiveram expressão no âmbito do trabalho docente e na definição de novos estabelecimentos de ensino [privados] que não enfatizassem o tripé educativo e privilegiassem contratos de trabalho flexíveis, mais ágeis, econômicos, temporários, contribuindo, assim, para a expansão da educação superior, tendo em vista a redução de critérios para o funcionamento das Instituições de Ensino Superior (IES). Nessa direção, a educação superior assume papel estratégico, na medida em que está diretamente relacionada às transformações econômicas da sociedade.

O horizonte da educação superior que se delineou principalmente de 1990 para os dias atuais é marcado pela fragilidade do financiamento público, que é orientado por indicadores ou metas de produtividade e concebido a partir da ideia de proteção do setor educacional, mediante vinculação orçamentária e, mais recentemente, destinação de vinculação a setores estratégicos nos quais a educação básica assume centralidade para os recursos públicos (PROTTI; LUQUE; CRUZ, 2012).

Em contrapartida, as formas de financiamento de que as IES públicas dispõem estão baseadas, essencialmente, nas transferências de recursos advindos do Tesouro Nacional (no caso das instituições federais de ensino superior - IFES) e nos repasses estaduais e municipais dos impostos arrecadados (para as instituições estaduais e municipais de ensino superior - IEES, IMES).

A ausência de uma subvinculação definida para o financiamento das universidades estaduais tem suscitado ampla discussão no país, principalmente no espaço dos movimentos docentes, que vêm imprimindo esforços mediante debates em seminários e mobilização conjunta de associações ${ }^{1}$. O objetivo é efetivar recursos específicos que garantam a manutenção das instituições e, desse modo, superar os limites impostos ao financiamento do

1 São realizados anualmente reuniões, encontros e marchas de protestos com a participação de mais de 40 associações docentes do país para discussões acerca do financiamento das instituições estaduais e municipais de educação superior (ADUSP, 2013). 
espaço público da educação superior demarcado pelas novas políticas empreendidas pelo Estado de matriz neoliberal.

\section{A Expansão da Educação Superior: o caso da UEPA}

No estado do Pará, se identifica apenas uma universidade estadual, a Universidade do Estado do Pará, criada em 1993, que se constitui como autarquia de regime especial e está organizada em multicampi presentes em 16 municípios do estado (UEPA, 2014). Segundo dados do Censo da Educação Superior (INEP, 2015), é a segunda maior universidade estadual da região norte (de um total de cinco), considerando o número de matrículas em cursos de graduação presenciais, e representa $21,4 \%$ das matrículas em cursos de graduação presenciais das IEs públicas do Pará2.

Contudo, no contexto político descrito, esse bem público sofre um processo de sucateamento e degradação para, ante a atual conjuntura de abandono da educação superior pública e gratuita ${ }^{3}$, justificar o processo de privatização. Na Tabela 1, é possível verificar a evolução de matrículas na educação superior em universidades estaduais, em níveis nacional, regional e estadual, no período de 2003 a 2010.

Tabela 1 - Evolução de Matrículas em Cursos de Graduação Presenciais, em Universidades Públicas e Universidades Estaduais - Brasil, Região Norte e Pará - 2003 a 2010

\begin{tabular}{c|cc|c|c|c|c}
\hline \multirow{2}{*}{ Ano } & \multicolumn{2}{|c|}{ Brasil } & \multirow{2}{*}{ Norte } & Pará & \multirow{2}{*}{ Pará/Norte (\%) } & Norte/Brasil (\%) \\
\cline { 2 - 3 } & Públicas & Estaduais & & & & \\
\hline 2003 & 1.136 .370 & 404.821 & 32.329 & 7.628 & 23,6 & 8,0 \\
\hline 2004 & 1.178 .328 & 429.823 & 35.716 & 8.950 & 25,1 & 8,3 \\
\hline 2005 & 1.192 .189 & 433.692 & 31.070 & 9.047 & 29,1 & 7,2 \\
\hline 2006 & 1.209 .304 & 436.662 & 37.378 & 10.345 & 27,7 & 9,6 \\
\hline 2007 & 1.240 .968 & 439.585 & 43.603 & 11.081 & 25,4 & 9,6 \\
\hline 2008 & 1.273 .965 & 446.832 & 42.735 & 12.544 & 29,4 & 7,3 \\
\hline 2009 & 1.351 .168 & 437.044 & 31.928 & 8.205 & 25,7 & 8,3 \\
\hline 2010 & 1.461 .696 & 471.269 & 39.349 & 12.440 & 31,6 & - \\
\hline$\Delta(\%)$ & 28,6 & 16,4 & 21,7 & 63,1 & - & \\
\hline
\end{tabular}

Fonte: INEP (2003-2010).

Constata-se que, nos anos em foco, em todo o Brasil houve reduzido aumento de matrículas em cursos de graduação presenciais das universidades estaduais. $\mathrm{O}$ crescimento que se visualiza nas instituições estaduais, no país, é menor que o crescimento observado no total das IEs públicas, o que é reflexo de uma política tímida dos estados com a educação superior pública e gratuita.

Em contraste, no Pará, as matrículas na UEPA aumentaram de modo significativo. O movimento expresso na Tabela 1 demonstra que a taxa de evolução anual, no Brasil, para as

2 As demais matrículas em cursos de graduação presenciais estão distribuídas entre a Universidade Federal do Pará (UFPA), com 56,0\%, a Universidade Federal Rural da Amazônia (UFRA), com 9,0\%, a Universidade Federal do Oeste do Pará (UFOPA), com $8,9 \%$ e a Universidade Federal do Sul e Sudeste do Pará (UNIFESSPA), com 4,7\% (INEP, 2015).

3 Destaca-se, para ilustrar esse panorama, a realidade que a Universidade do Estado do Rio de Janeiro (UERJ) vivencia, de completo abandono por parte do governo do estado, numa nítida demonstração de incompetência técnica e política com o gerenciamento do espaço público (MEROLA, 2017). 
matrículas em cursos de graduação presenciais nas universidades estaduais, esteve na ordem de 2,2\% ao ano, o que perfaz o total de 16,4\% no período em análise. Esses valores são maiores para a região norte e, particularmente, para o estado do Pará, que manteve percentuais de crescimento superiores à média nacional de crescimento das matrículas presencias em universidades estaduais.

Fruto de uma política expansionista dos governos federal e estaduais que articulam os privilégios ao setor educacional privado com a degradação do ensino superior público, esse movimento da expansão no setor público segue dois critérios: i) fortalecimento do setor privado em detrimento do público e ii) expansão tardia das matrículas na região norte. Vale notar que o setor privado, no mesmo período, cresceu $45,0 \%$, considerando todas as instituições desse setor, com média anual de 5,5\% (INEP, 2003-2010)4.

No tocante ao Pará e à região norte, observa-se que os valores absolutos oscilam em alguns anos, ora apresentando crescimento e ora redução, instigando a reflexão sobre o caráter ou a condução dessa política de expansão superior no referido estado e região. Ainda assim, verifica-se que a UEPA, com exceção de nos últimos dois anos (em especial no ano de 2009), apresentou aumentos seguidos nas matrículas, resultando num acréscimo de $63,1 \%$, ao final do período em estudo, com média de crescimento anual na ordem de $10,0 \%$.

É importante destacar que a expansão vivenciada na UEPA nos anos destacados esteve orientada por duas gestões historicamente divergentes em âmbito estadual, conforme evidenciado pelos discursos de seus protagonistas. O governador Simão Jatene (PSDB), no período de 2003 a 2006, e a governadora Ana Júlia Carepa (PT), de 2007 a 2010. Desde a Constituinte até 2006, quando Ana Júlia Carepa foi eleita, o Pará esteve sob o domínio de partidos tradicionalmente de direita, e a UEPA esteve subordinada a eles desde a sua criação em 1993.

Um partido dos trabalhadores no poder trazia consigo, em princípio, uma expectativa diferencial para o trato com o financiamento da educação superior, porém, uma vez que o PT já estava à frente das ações do Estado em âmbito federal desde 2003, sob a tutela do então presidente Luís Inácio Lula da Silva, não se tinha expectativa de uma ruptura profunda na forma de governar durante a gestão de Ana Júlia Carepa. De fato, em seus anos iniciais, o governo Lula havia demonstrado que seria marcado por políticas voltadas ao fortalecimento da esfera privada na oferta da educação superior, por meio de programas como o FIES ${ }^{5}$ e o PROUNI ${ }^{6}$. No entanto, para uma análise mais detida do que representou a expansão da UEPA

4 Em 1995, o Banco Mundial, por meio da publicação do documento "A Educação Superior: as lições derivadas da experiência", expôs quatro pontos centrais para a orientação das reformas na Educação Superior para a América Latina e o Caribe, são eles: "1. Fomentar la mayor diferenciación de las instituciones, incluido el establecimiento de instituciones privadas; 2. Proporcionar incentivos para que las instituciones públicas diversifiquen las fuentes de financiamiento, entre ellas, la participación de los estudiantes en los gastos, y la estrecha vinculación entre el financiamiento fiscal y los resultados; 3. Redefinir la función del gobierno en la enseñanza superior; 4. Adoptar políticas que estén destinadas concretamente a otorgar prioridad a los objetivos de calidad y equidad" (BANCO MUNDIAL, 1995, p. 29).

5 Política de concessão de financiamento para estudantes regularmente matriculados em cursos de graduação de instituições particulares de educação superior, aprovado por meio da Lei $n^{\circ} 10.260$, de 12 de julho de 2001 (BRASIL, 2001).

6 Concessão de bolsas integrais e parciais para estudantes de instituições particulares de educação superior, aprovado por meio da Lei n 11.096, de 13 de janeiro de 2005 (BRASIL, 2005). 
nos governos mencionados, apresenta-se a Tabela 2 que expõe a evolução de cursos, de matrículas e de funções docentes na UEPA.

Tabela 2 - Expansão dos Cursos, das Matrículas e das Funções Docentes, em Exercício e Afastados, na Graduação Presencial - UEPA - 2003 a 2010

\begin{tabular}{ccccc}
\hline Ano & Cursos & Matrículas & $\begin{array}{c}\text { Funções } \\
\text { Docentes }\end{array}$ \\
\hline 2003 & 52 & 7.571 & 614 \\
\hline 2004 & 68 & 8.950 & 587 \\
\hline 2005 & 76 & 9.047 & 587 \\
\hline 2006 & 73 & 10.345 & 761 \\
\hline 2007 & 72 & 11.081 & 890 \\
\hline 2008 & 71 & 12.544 & 946 \\
\hline 2009 & 83 & 8.205 & 994 \\
\hline 2010 & 87 & 12.440 & 1.132 \\
\hline$\Delta(\%) 2003-2006$ & 40,4 & 36,6 & 23,9 \\
\hline$\Delta(\%) 2007-2010$ & 20,8 & 12,2 & 27,2 \\
\hline$\Delta(\%) 2003-2010$ & 67,3 & 64,3 & 84,4 \\
\hline \multicolumn{5}{c}{ Fonte: INEP $(2003-2010)}$.
\end{tabular}

Percebe-se que, no período em estudo, a UEPA amplia cursos, matrículas e número de docentes. Essa evolução se dá de forma quase equiparada, particularmente em função de uma expansão no quadro docente, fruto dos concursos públicos realizados em 2007 e 2010 que foram conquistados após os processos de luta travados pelos docentes e técnicoadministrativos desde 2004-2005 até o período em questão.

No governo de Simão Jatene, a UEPA apresentou uma importante expansão no que diz respeito aos cursos e matrículas, mas que não foi acompanhada pelas funções docentes. Essa problemática, somada à pauta salarial, não proporcionou as condições necessárias para o desenvolvimento qualitativo das atividades acadêmicas, o que despertou os servidores para um processo de luta, já em 2005, sendo que, naquele momento, reivindicavam:

\section{[...] a necessidade de efetivos investimentos financeiros e de infraestrutura nas áreas de Ensino, Pesquisa e Extensão, tanto na capital como no interior. Registrando que, nos campi interiorizados, na sua grande maioria, não existem bibliotecas, laboratórios e, muito menos, a manutenção dos laboratórios de informática. Havendo urgência em incentivar a política de bolsas para Iniciação Científica, Monitoria, Campus Avançado como extensão universitária para o Interior do Estado, em cumprimento ao art. 207 da Constituição Federal, que trata da exigência da indissociabilidade entre o Ensino, a Pesquisa e a Extensão (SINDUEPA; SINTAUEPA, 2005, p. 3-4, grifo nosso).}

Desde 2005, as reivindicações perpassaram por um eixo central: as condições financeiras ofertadas às universidades estaduais. No governo Ana Júlia Carepa, a expansão se deu de forma mais comedida, e o quadro de funções docentes foi ampliado em maior grau, comparado ao número de cursos e matrículas, fechando o período de sua gestão com crescimento de $27,2 \%$ em relação ao quadro de 2007 , ano em que houve o importante aumento de $17,0 \%$ nessas funções, graças à abertura de concurso, como já mencionado. Assim, a ampliação geral do quadro docente no total do período acabou por fechar em $84,4 \%$, o que possibilitou que essa expansão fosse maior que a dos cursos e matrículas. Desse modo, foi amenizada, no panorama geral do período, a avaliação da intensificação do trabalho docente, predominante no governo Simão Jatene. 
$\mathrm{Na}$ comparação entre os dois períodos de governos, é possível notar que, contraditoriamente, se no governo de Simão Jatene ocorreu forte aumento em cursos e matrículas (da ordem de 40,4\% e 36,6\%, respectivamente), isso se deu à custa dos docentes, cujo quadro aumentou em apenas $23,9 \%$. Já em relação ao governo Ana Júlia, ocorreu o contrário: o quadro docente expandiu em $27,2 \%$, enquanto o aumento de cursos e matrículas correspondeu, respectivamente, a $20,8 \%$ e $12,2 \%$, e isso resultou nessa expansão mais equiparada.

No entanto, para melhor avaliar o fato de governos que expandem a universidade pública, é necessário estabelecer relações para verificar o quanto foi despendido em recursos que visassem ao acompanhamento e à manutenção dessa expansão. Nesse sentido, a Tabela 3 apresenta a comparação entre o Produto Interno Bruto (PIB) do estado e o montante de recursos executados na UEPA de 2003 a 2010, a fim de demonstrar, em termos percentuais, o que os gastos com a UEPA representam frente ao PIB estadual.

Tabela 3 - PIB do Pará, Execução Orçamentária do Pará e Execução Orçamentária da UEPA 2003 a $2010^{7}$

\begin{tabular}{|c|c|c|c|c|c|}
\hline Ano & PIB-PA & PARÁ & UEPA & UEPA/PARÁ & UEPA/PIB-PA \\
\hline 2003 & 62.259 .007 & 9.127 .995 & 99.439 & $1,09 \%$ & $0,16 \%$ \\
\hline 2004 & 69.806 .528 & 9.990 .449 & 105.454 & $1,06 \%$ & $0,15 \%$ \\
\hline 2005 & 71.854 .581 & 10.457 .886 & 115.715 & $1,11 \%$ & $0,16 \%$ \\
\hline 2006 & 78.222 .086 & 12.244 .544 & 138.455 & $1,13 \%$ & $0,18 \%$ \\
\hline 2007 & 84.212 .766 & 12.951 .032 & 154.554 & $1,19 \%$ & $0,18 \%$ \\
\hline 2008 & 94.192 .833 & 15.100 .525 & 188.112 & $1,25 \%$ & $0,20 \%$ \\
\hline 2009 & 89.624 .031 & 15.669 .316 & 185.292 & $1,18 \%$ & $0,21 \%$ \\
\hline 2010 & $\begin{array}{c}113.734 .55 \\
6\end{array}$ & 17.468 .368 & 199.407 & $1,14 \%$ & $0,18 \%$ \\
\hline$\Delta(\%)$ 2003-2006 & 25,6 & 34,1 & 39,2 & - & - \\
\hline$\Delta(\%)$ 2007-2010 & 35,0 & 34,9 & 29,0 & - & - \\
\hline$\Delta(\%)$ 2003-2010 & 82,7 & 91,4 & 100,5 & - & - \\
\hline
\end{tabular}

A Tabela 3 evidencia que houve um incremento significativo em termos absolutos tanto do PIB quanto nas execuções orçamentárias do Estado do Pará e da UEPA. Contudo, há descompassos entre os dois períodos de governo em análise quando visualizados os percentuais de crescimento das três variáveis expostas na Tabela 3 . O crescimento do PIB e do orçamento do Pará no governo Simão Jatene são inferiores à evolução dos gastos com a UEPA, ao passo que, no governo Ana Júlia, essa lógica se inverte.

Destaca-se que o crescimento observado no período é real, considerando-se os dados inflacionários, o que demonstra um movimento de evolução efetivo. Porém, quando se analisam os percentuais do PIB e do orçamento do Estado do Pará destinados à UEPA, verifica-se que estes são ínfimos e que, no período em análise, o incremento foi discreto.

7 Os dados financeiros expostos neste artigo se encontram corrigidos pela inflação e expressam valores de janeiro de 2016. O deflator utilizado é o Índice Nacional de Preços ao Consumidor Amplo (IPCA) do Instituto Brasileiro de Geografia e Estatística (IBGE). 
Ainda em relação ao financiamento, embora nos anos de 2008 e 2009 tenha havido uma ampliação do percentual de recursos injetados na UEPA frente ao PIB, em 2010 (ano de significativo aumento do PIB), o ciclo acabou fechando com percentual equivalente ao do fechamento do governo Simão Jatene de 2006, apenas $0,18 \%$, que é um valor claramente insuficiente. Esse movimento é observado também em relação à proporção do orçamento da UEPA sobre o orçamento do Pará, um crescimento tímido até 2008 , seguido de uma queda até 2010. Isso quer dizer que ambos os governos expandem a universidade pública, mas a repercussão financeira é diminuta se comparada ao PIB e ao orçamento do Pará.

Quando se analisam os dados dos Balanços Gerais do Estado, é possível estabelecer uma segunda comparação que demonstra a capacidade de arrecadação do estado do Pará no período em questão. Tal capacidade está expressa no Gráfico 1 a partir dos recursos destinados com a Manutenção e Desenvolvimento do Ensino (MDE).

\section{Gráfico 1 - Execução da Manutenção e Desenvolvimento do Ensino e Orçamento da UEPA (em relação à MDE, em \%) - 2003 a 2010}

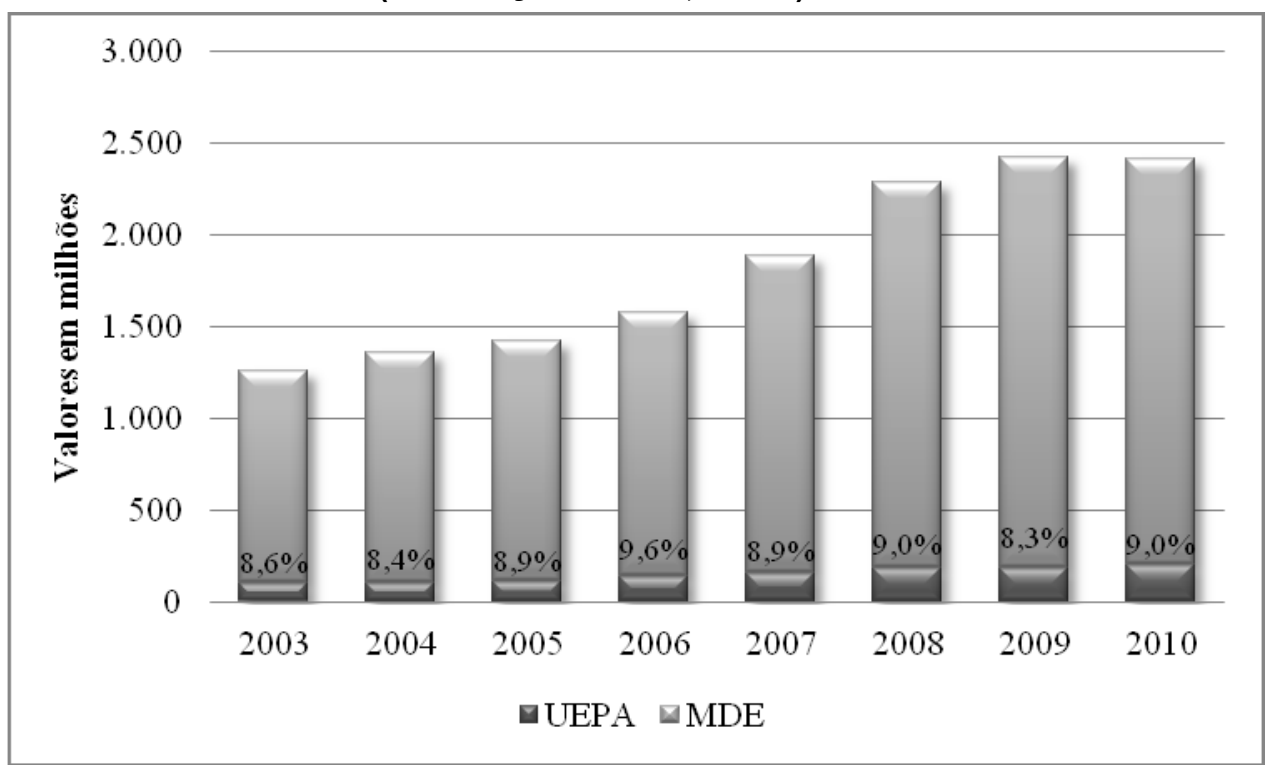

Fonte: Pará (2003-2010)

Os recursos que compõem à MDE são oriundos da arrecadação por meio de impostos, não da receita bruta, mas da receita líquida, após a realização das transferências constitucionais previstas entre os entes federados e a união. Para o cálculo da MDE, conforme a Constituição do Pará, aplica-se ao montante bruto da arrecadação líquida dos impostos o percentual mínimo de 25\%, definido no caput do Art. 212 da Constituição Federal (1988).

O Gráfico 1 expressa a proporção que a UEPA ocupa no todo do MDE do estado do Pará. Constata-se que a UEPA ocupa uma parcela minoritária no todo do MDE, oscilando de $8,3 \%$ a $9,6 \%$ no período em análise, com média de $8,8 \%$ (8,87\% no governo Simão Jatene e $8,80 \%$ no governo Ana Júlia). Dessa forma, não se visualiza uma política do estado do Pará que garanta recursos acima dos incluídos na MDE para a configuração do orçamento da UEPA, tal como se verifica no financiamento de algumas universidades estaduais no Brasil.

Acerca da forma específica do financiamento para as universidades estaduais no Brasil e sua relação com à MDE, Carvalho $(2014$, p. 14$)$ identificou que a maioria das unidades federativas mantém os $25 \%$ como percentual mínimo para ser investido em educação. No 
O Financiamento das IEEs Brasileiras frente ao Processo de Expansão da Educação Superior

entanto, apenas nove estados ampliaram esse percentual, a saber: Amapá (28\%); Goiás (28,25\%); Acre, Piauí, São Paulo e Paraná (30\%); Mato Grosso, Rio de Janeiro e Rio Grande do Sul (35\%).

Ainda acerca do financiamento das universidades estaduais, a autora destaca a necessidade da subvinculação de recursos para essas instituições, quer seja por meio de percentuais fixos dos recursos oriundos da MDE, quer seja a partir da subvinculação diretamente atrelada aos impostos. Dos oito estados que apresentam alguma subvinculação, apenas o estado de São Paulo não o faz a partir da MDE: este mantém os recursos para o financiamento das três universidades paulistas com $9,57 \%$ do que é arrecadado de ICMS (CARVALHO, 2014).

Portanto, a presença de uma subvinculação legalmente garantida é indispensável para que uma universidade planeje suas ações de ensino, de pesquisa e de extensão, entre tantas outras atividades pelas quais é responsável. Além disso, a falta de uma previsão de recursos dificulta até mesmo o controle social, pois os recursos para financiamento são sempre uma caixinha de surpresas, que dependerá de muitos fatores, inclusive da vontade política.

Em uma análise detida referente aos recursos executados pela UEPA, identificam-se indícios da ausência de uma política de financiamento da educação superior, em especial em períodos de acentuada expansão. Os Balanços Gerais do Estado do Pará demonstram um aumento em valores absolutos dos recursos, tanto no período de 2003 a 2006, quanto de 2007 a 2010, conforme dados expostos na Tabela 3 (coluna 3).

A Tabela 4 abaixo ajuda na análise comparativa da situação da UEPA, sendo sua segunda coluna simplesmente a reprodução da quarta coluna da Tabela 3: corresponde ao total executado no financiamento da UEPA. Há também um crescimento continuado, com exceção de uma pequena queda em 2009.

A variação apresentada nas colunas 3 e 5 da Tabela 4 corresponde à diferença percentual em relação ao ano anterior. Nesta mesma tabela, na coluna 4, encontra-se o montante referente aos investimentos realizados na UEPA, entenda-se esses como recursos novos para acompanhar o movimento de expansão, sobretudo no que tange a estrutura da universidade para abarcar novos cursos e possibilitar novas matrículas.

Tabela 4 - Orçamento Executado e Investimentos na UEPA - 2003 a 2010

\begin{tabular}{c|c|c|c|c}
\hline \multirow{2}{*}{ Ano } & $\begin{array}{c}\text { Orçamento } \\
\text { Executado }\end{array}$ & $\begin{array}{c}\text { Variação } \\
(\%) \text { a.a }\end{array}$ & $\begin{array}{c}\text { Investimentos } \\
\text { (rec. novos) }\end{array}$ & $\begin{array}{c}\text { Variação (\%) } \\
\text { a.a }\end{array}$ \\
\hline 2003 & 99.439 & - & 5.646 & - \\
\hline 2004 & 105.454 & 6,0 & 7.627 & 35,1 \\
\hline 2005 & 115.715 & 9,7 & 7.013 & $-8,1$ \\
\hline 2006 & 138.455 & 19,7 & 10.086 & 43,8 \\
\hline 2007 & 154.554 & 11,6 & 8.367 & $-17,0$ \\
\hline 2008 & 188.112 & 21,7 & 26.257 & 213,8 \\
\hline 2009 & 185.292 & $-1,5$ & 13.294 & $-49,4$ \\
\hline 2010 & 199.407 & 7,6 & 11.027 & $-17,1$ \\
\hline$\Delta(\%) 2003-2006$ & 39,2 & - & 78,6 & - \\
\hline$\Delta(\%) 2007-2010$ & 29,0 & - & 31,8 & - \\
\hline$\Delta(\%) 2003-2010$ & 100,5 & - & 95,3 & \\
\hline \multicolumn{7}{c}{ Fonte: Pará (2003-2010). }
\end{tabular}


O Financiamento das IEEs Brasileiras frente ao Processo de Expansão da Educação Superior

A grande variação dos percentuais ano a ano demonstra a variabilidade no repasse desses recursos para a UEPA, tanto os destinados à manutenção quanto, e principalmente, ao investimento ao longo dos anos que percorreram as duas gestões governamentais. Em relação ao investimento, salienta-se como exemplo marcante, o importante crescimento observado no ano de 2008, seguido do significativo decréscimo que foi verificado logo no ano seguinte em 2009.

A Tabela 4 expressa, além disso, particularidades dos governos no que diz respeito aos investimentos. Ao se observar simplesmente os anos iniciais e finais de cada gestão, o governo Simão Jatene ampliou em $78,6 \%$ os recursos de investimentos, enquanto no de Ana Júlia Carepa esse acréscimo ficou na ordem de 31,8\%. Contudo, vale destacar, que o montante absoluto de recursos injetados em investimentos nos dois governos expressa uma dinâmica inversa da evolução percentual. O governo Ana Júlia Carepa investiu quase o dobro (somatória dos valores absolutos) do governo Simão Jatene: foram R $\$ 58.945$ milhões contra $\mathrm{R} \$ 30.372$ milhões.

A comparação entre os referidos governos pode ser percebida de forma mais evidente no Gráfico 2. Quando foi tomada a referência no PIB, o governo Ana Júlia Carepa aparentava investir mais na universidade. No entanto, nos gráficos, percebe-se que este foi o período em que houve maior variação no volume de recursos executados tanto em aumentos quanto em quedas. Isso se acentua ainda mais nos investimentos, conforme os dados da Tabela 4.

\section{Gráfico 2 - Orçamento da UEPA nos Governos Simão Jatene e Ana Júlia - 2003 a 2010}

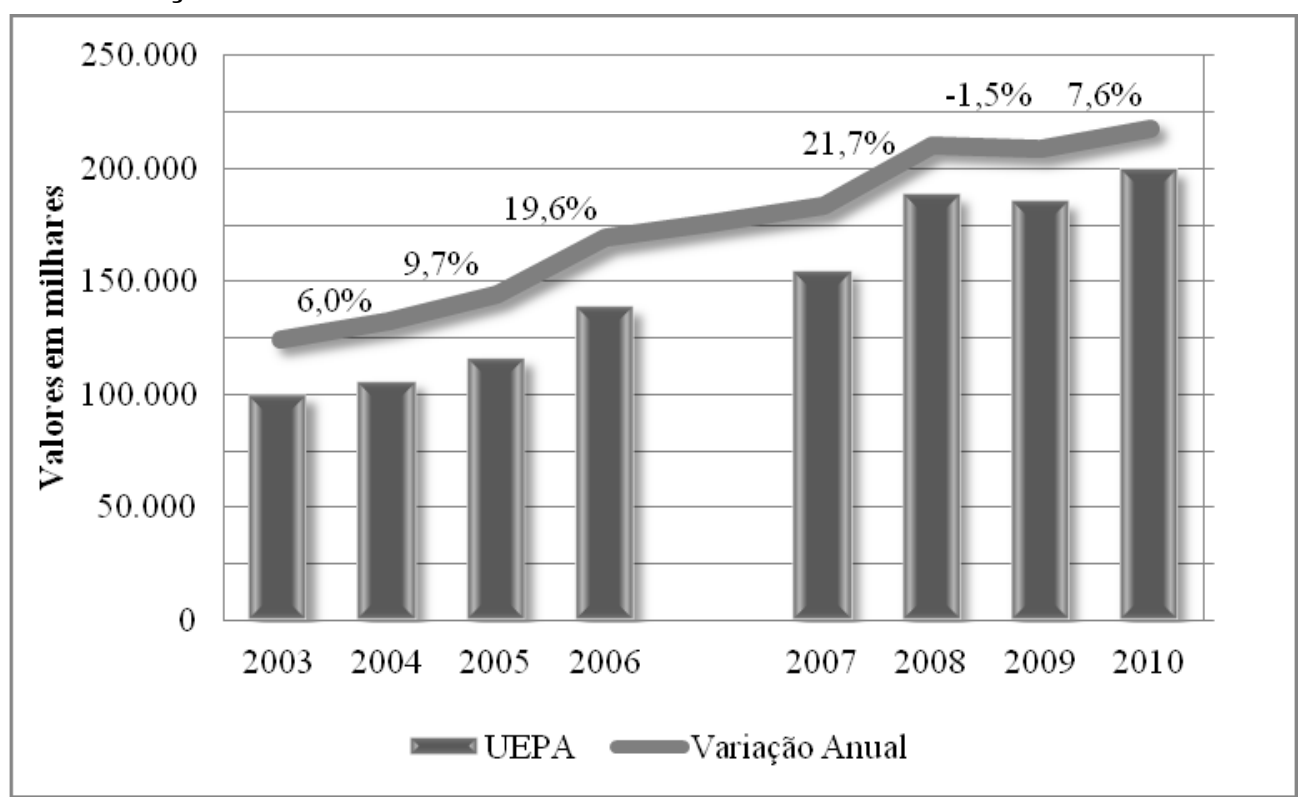

Fonte: Pará (2003-2010).

Os dados apresentados por meio do Gráfico 2 conseguem expressar o movimento de evolução do financiamento para a UEPA ao longo dos dois governos. Destacam-se acréscimos importantes no período 2003-2006 do governo Simão Jatene, com variações anuais acima dos 6,0\%. O período 2007-2010 da gestão Ana Júlia Carepa apresenta um avanço importante de 2007 para 2008, como já destacado aqui, também em virtude do concurso público no ano de 2007. Este, entretanto, segue com um pequeno crescimento até 2010 e um decréscimo em 2009. 
A inconstância dos recursos para a manutenção de uma IES pressiona esta a atender a uma das orientações dos organismos internacionais que já foi bastante propalada, a diversificação das fontes de financiamento, uma vez que a incerteza no repasse de recursos para a instituição acarreta o movimento da gestão superior pela busca de fonte complementar, por meio de parcerias, convênios, aluguel do espaço público e cobrança de taxas diversas. $O$ fato é que a UEPA, constantemente, está imersa em políticas de contenção de gastos.

Ao investigar os gastos que a UEPA realizou, o seguinte cenário foi identificado:

Tabela 5 - Execução Orçamentária por Grupo de Natureza de Despesa ${ }^{8}$ - 2003 a 2010

$(\mathrm{R} \$ 1.000,00)$

\begin{tabular}{c|cc|c|c|c|c}
\hline Ano & Pessoal & $\Delta(\%)$ a.a. & Investimentos & $\begin{array}{c}\Delta(\%) \\
\text { a.a. }\end{array}$ & $\begin{array}{c}\text { Outras } \\
\text { Despesas } \\
\text { Correntes }\end{array}$ & $\Delta(\%)$ a.a. \\
\hline 2003 & 52.641 & - & 5.646 & - & 41.089 & - \\
\hline 2004 & 55.919 & 6,2 & 7.627 & 35,1 & 41.612 & 1,3 \\
\hline 2005 & 66.491 & 18,9 & 7.013 & $-8,0$ & 42.210 & 1,4 \\
\hline 2006 & 87.916 & 32,2 & 10.086 & 43,8 & 40.452 & $-4,2$ \\
\hline 2007 & 100.378 & 14,2 & 8.367 & $-17,0$ & 45.808 & 13,2 \\
\hline 2008 & 109.921 & 9,5 & 26.257 & 213,8 & 51.933 & 13,4 \\
\hline 2009 & 117.384 & 6,8 & 13.294 & $-49,4$ & 54.613 & 5,2 \\
\hline 2010 & 125.376 & 6,8 & 11.027 & $-17,0$ & 63.003 & 15,4 \\
\hline$\Delta(\%) 2003-2006$ & 67,0 & - & 78,6 & - & $-1,5$ & - \\
\hline$\Delta(\%) 2007-2010$ & 24,9 & - & 31,8 & - & 37,5 & - \\
\hline$\Delta(\%) 2003-2010$ & 138,2 & - & 95,3 & - & 53,3 & - \\
\hline
\end{tabular}

Foi visto na Tabela 2 que o percentual de aumento nas funções docentes de 2006 a 2010 foi de $48,7 \%$. Dessa forma, o crescimento com gastos para pagamento de pessoal era inevitável. No entanto, conforme a Tabela 5, no governo de Ana Júlia, excetuando-se o ano de 2007, houve menor percentual de crescimento nas despesas com pessoal, após a importante elevação nesse valor em 2006. Os períodos dos governos apresentam diferenças significativas no que concerne aos gastos com pessoal. O governo Simão Jatene ampliou em $67,0 \%$, e o governo Ana Júlia Carepa ficou na ordem de $24,9 \%$ apenas.

O movimento se inverte quando se visualizam os gastos com outras despesas correntes, que implica nos recursos necessários para a manutenção do funcionamento da instituição. No período de 2003 a 2006, a UEPA funcionou, praticamente, com o mesmo volume de recursos e, como demonstrado na Tabela 2, ocorreu crescimento do número de cursos e de matrículas. Ao longo do segundo período houve crescimento do volume destinado para outras despesas correntes na ordem de $37,5 \%$.

Nos Gráficos 3 e 4 estão sintetizados, para uma confrontação visual, os gastos por natureza de despesa em cada governo, que foram apresentados na Tabela 5 a fim de melhor analisar.

8 O Grupo por Natureza de Despesa (GND) corresponde a um agregador de item de despesa com as mesmas características quanto ao objeto consumido. O uso deste dado nos possibilita iniciar a discussão sobre o gerenciamento dos recursos executados a fim de aprofundar nossas análises (BRASIL, 2017). 
O Financiamento das IEEs Brasileiras frente ao Processo de Expansão da Educação Superior

Gráfico 3 - Governo Simão Jatene

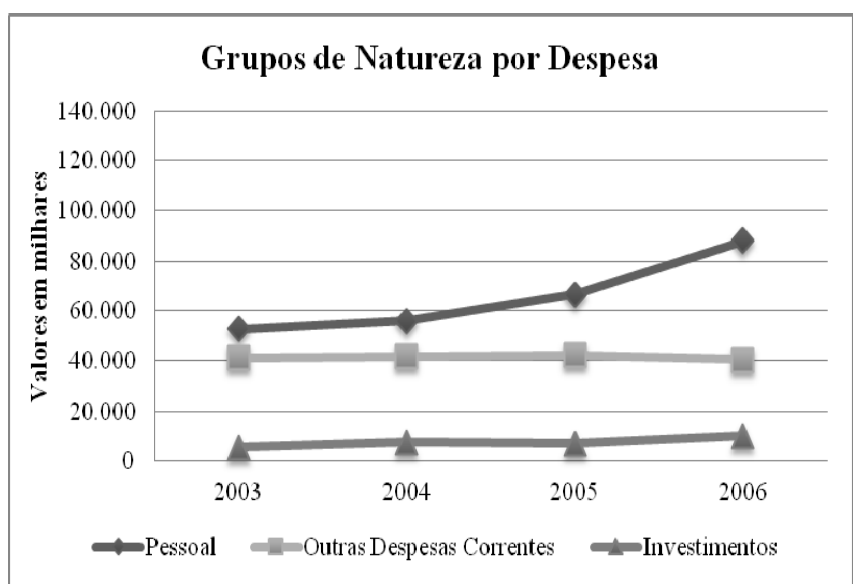

Fonte: Pará (2003-2010).
Gráfico 4 - Governo Ana Júlia

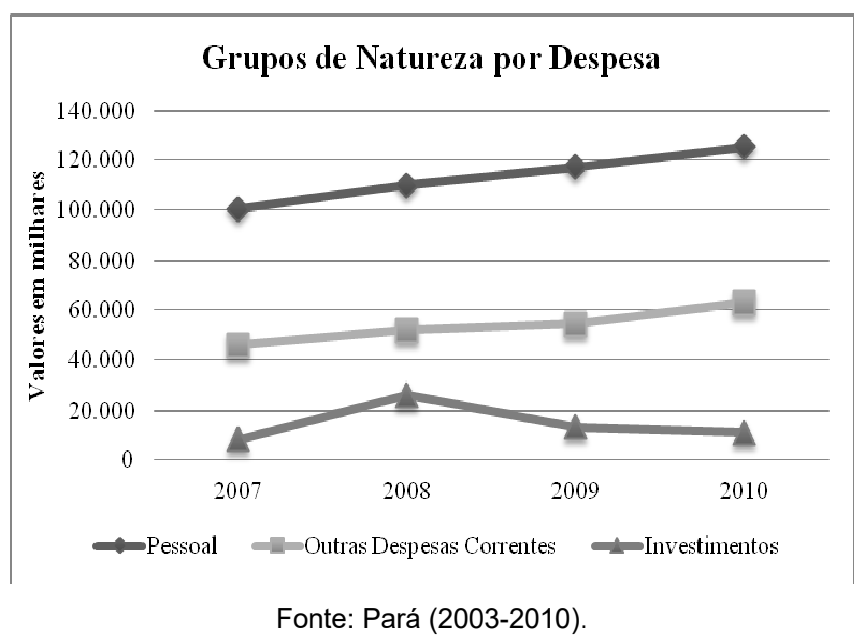

Em síntese, percebe-se pelos Gráficos 3 e 4 que os gastos com pessoal foram crescentes nos dois governos, observando-se um crescimento quase linear de 2007 a 2010 e um aumento considerável de 2005 a 2007, época dos concursos de ingresso docente antes destacados. Por outro lado, os gastos com outras despesas correntes foram basicamente constantes no governo PSDB e também crescentes no governo do PT. Em contrapartida, os gastos com investimentos são basicamente constantes no governo Simão Jatene e oscilam de modo importante no governo Ana Júlia Carepa, salientando-se um pico correspondente a 26 milhões em 2008 e uma forte queda a partir desse ano.

Portanto, ao quantificar o financiamento de uma universidade multicampi, como é o caso da UEPA, que vivencia um amplo processo de expansão e interiorização, pode-se depreender que os valores repassados a essa instituição não dão conta de financiar as atividades fins que ela desempenha. A política de expansão, sem a efetivação de mais recursos para o acompanhamento dessa expansão, conduz ao sucateamento da universidade e força o estreitamento desta com o setor privado, onde vai captar recursos para incrementar seu orçamento.

\section{Considerações Finais}

Diante do cenário exposto, há conviç̧ão de que a Reforma do Aparelho do Estado trouxe uma nova lógica de funcionamento para o Estado e para as políticas públicas e sociais. Estas, além disso, trazem grandes impactos para a educação superior brasileira, principalmente para as IEES, onde o desafio se torna mais árduo, dada a pouca participação federal (que se dá principalmente para financiar ações e programas determinados pelo MEC ou relacionados com ações da política educacional nacional). São parcos os recursos transferidos pelos estados às suas universidades, o que se deve também à orientação internacional dos organismos multilaterais de que a destinação dos recursos deva ser preferencialmente à educação básica.

Sobre a situação da UEPA durante o governo do PT de Ana Júlia Carepa, as primeiras impressões indicam um processo de expansão equiparado entre alguns dos sujeitos que compõem a universidade - estudantes matriculados e docentes. No entanto, a impressão de que esse governo investiu mais na educação superior pública cai por terra quando se compara 
a execução orçamentária da UEPA ao PIB e ao Orçamento do Pará, já que, em média, a razão entre esses montantes não é modificada de modo considerável, permanecendo muito abaixo do necessário. Em particular, essa razão não apresentou ampliação no último ano de governo de Ana Júlia Carepa quando comparada ao último ano de Simão Jatene (2006), pois a UEPA foi financiada por apenas $0,18 \%$ do Produto Interno Bruto, em ambos. Esse montante é extremamente baixo sob qualquer referência que se queira invocar, como, por exemplo, os Planos Nacionais e Estaduais de Educação, produzidos nas últimas décadas.

O financiamento da UEPA, em governos tão divergentes ideologicamente, não evidenciou rupturas quanto à função que a educação superior assume no cenário estadual, haja vista que alguns desafios ainda persistem, quais sejam: quando se promove uma expansão tão importante de cursos e estudantes matriculados, como a que ocorreu entre 2003 e 2010 no Pará, o investimento precisaria ser crescente em relação ao PIB do estado. Além disso, a subvinculação constitucional de recursos para a UEPA deveria ser instituída, e a lógica de destinar recursos conforme a vontade política, definitivamente banida.

Em resumo, embora a receita do estado tenha se mantido em crescimento, acima da inflação, durante as duas gestões de governo do Pará correspondentes ao período em análise, a execução orçamentária da UEPA com os recursos repassados para a universidade se manteve no mesmo patamar relativo de, aproximadamente, $0,2 \%$ do PIB. Os investimentos são parcos, enquanto que a despesa com pessoal, embora em patamar inferior ao necessário, cresce em virtude do significativo aumento de estudantes matriculados e do aumento de funções docentes, bem como dos movimentos de resistência de técnicos e docentes frente às tentativas de rebaixamento salarial e aumento excessivo da carga de trabalho. É urgente rever a lógica do subfinanciamento dessa importante IEES.

Finalmente, apesar de não ter sido foco deste estudo, vale acrescentar que, no período de 2011 a 2014, não houve mudança no cenário do financiamento da UEPA. As inconstâncias e involuções de gastos continuam marcantes. Em 2012, os gastos com investimentos foram de $\mathrm{R} \$$ 9.701.942,00 e, em 2014, decresceram para $\mathrm{R} \$ 4.139 .602,00$.

O cenário que se evidencia para as universidades públicas é de crise institucional, que de acordo com Santos (2010, p. 15-16) implica em afirmar que:

A crise institucional era e é, desde há pelo menos dois séculos, o elo mais fraco da universidade pública porque a autonomia cientifica e pedagógica da universidade assenta na dependência financeira do Estado. Enquanto a universidade e os seus serviços foram um inequívoco bem público que competia ao Estado assegurar, esta dependência não foi problemática, à semelhança do que se passa, por exemplo, com o sistema judicial, em que a independência dos tribunas não é beliscada pelo fato de serem financiados pelo Estado. No entanto, ao contrário do que se passou com a justiça, decidiu reduzir o seu compromisso político com as universidades e com a educação em geral, convertendo esta num bem que, sendo público, não tem de ser exclusivamente assegurado pelo Estado, a universidade pública entrou automaticamente em crise institucional. Se esta existia antes, aprofundou-se. Pode-se dizer que nos últimos trinta anos a crise institucional da universidade na grande maioria dos países foi provocada ou induzida pela perda da prioridade do bem público universitário nas políticas públicas e pela consequente secagem financeira e descapitalização das universidades públicas.

A inadequação ou mesmo a redução dos recursos para a manutenção dessas instituições se ajusta às transformações gerenciais nas ações do Estado brasileiro e também 
O Financiamento das IEEs Brasileiras frente ao Processo de Expansão da Educação Superior

se refletem em seus entes federados, cujo objetivo central reside na redução dos gastos com as políticas públicas sociais e na adequação à nova ordem internacional vigente de crescente acumulação de capital e fortalecimento da lógica de mercado. Logo, a estratégia está em expandir a educação superior também por via das universidades estaduais, mas sob o ângulo economicista: com a contenção de despesas e um estímulo a uma maior abertura para parcerias público-privadas, captação de receitas próprias, bem como qualquer estratégia que fortaleça a lógica mercantil no interior das universidades públicas estaduais. Permite-se, assim, o mínimo de utilização do PIB estadual, enfraquecendo a demanda pela adoção de subvinculação de recursos públicos captados para a educação superior.

Considera-se que é necessário romper com a lógica de priorização da educação básica e que emerja uma concepção de educação superior com vistas a dar continuidade ao processo de formação emancipadora dos sujeitos para além de um nível básico de educação. É indispensável pensar na educação em todos os seus níveis, com destinação de recursos públicos exclusivos e suficientes para a educação pública.

\section{Referências}

ANDERSON, Perry. Balanço do Neoliberalismo. In: SADER, Emir; GENTILI, Pablo (Org.). Pós-Neoliberalismo: as políticas sociais e o estado democrático. Rio de Janeiro: Paz e Terra, 1995.

ADUSP - Associação dos Docentes da Universidade de São Paulo. O Setor das IEEs/IMEs se Reúne. São Paulo, 2013. Disponível em: <http://www.adusp.org.br/index.php/defesa-dauniversidade/1618-o-setor-das-iees-imes-se-reune>. Acesso em: 15 jan. 2016.

BANCO MUNDIAL. La Enseñanza Superior: las lecciones derivadas de la experiencia. Washington, 1995. Disponível em: <http://www-wds.worldbank.org/external/default/WDS ContentServer/WDSP/IB/2005/06/14/000090341_20050614161209/Rendered/PDF/133500P APER0Sp1riorOBox2150A1995001.pdf >. Acesso em: 8 nov. 2014.

BRASIL. Lei $n^{\circ} 10.260$, de 12 de julho de 2001. Dispõe sobre o Fundo de Financiamento ao estudante do Ensino Superior e dá outras providências. Diário Oficial [da] República

Federativa do Brasil, Brasília, DF, 13 jul. 2001. Disponível em: <http://www.planalto.gov.br/ccivil_03/leis/LEIS_2001/L10260.htm>. Acesso em: 18 maio 2017.

BRASIL. Lei n 11.096, de 13 de janeiro de 2005. Institui o Programa Universidade para Todos - PROUNI, regula a atuação de entidades beneficentes de assistência social no ensino superior; altera a Lei $n^{\circ} 10.891$, de 9 de julho de 2004, e dá outras providências. Diário Oficial [da] República Federativa do Brasil, Brasília, DF, 14 jan. 2005. Disponível em: <http://www.planalto.gov.br/ccivil_03/_ato2004-2006/2005/lei//11096.htm>. Acesso em: 18 maio 2017.

BRASIL. Ministério do Planejamento, Desenvolvimento e Gestão. Secretaria do Orçamento Federal. Manual Técnico do Orçamento. Brasília: MP, 2017.

CARVALHO, Cristina Helena Almeida de. Mapeamento do Financiamento à Educação Superior Estadual no Brasil: da vinculação de recursos e da evolução dos gastos com pessoal, custeio e investimento. In: SEMINÁRIO NACIONAL UNIVERSITAS/BR, 22., 2014, Natal. 
O Financiamento das IEEs Brasileiras frente ao Processo de Expansão da Educação Superior

Anais... Natal: Universidade Federal do Rio Grande do Norte, 2014. p. 9-26. Disponível em: <http://universitas.ce.ufrn.br/ANAIS_DO_XXII_SEMINARIO_NACIONAL_UNIVERSITAS.pdf >. Acesso em: 2 abr. 2015.

DOURADO, Luiz Fernando. A Reforma do Estado e as Políticas para a Educação Superior no Brasil nos Anos 90. Educação e Sociedade, Campinas, v. 23, n. 80, p. 234-252, set. 2002.

IBGE - Instituto Brasileiro de Geografia e Estatística. Produto Interno Bruto dos Municípios 2003-2007 (PIBMUN0307); 2005-2011 (PIBMUNIC). Rio de Janeiro, 2016. Disponível em: <http://downloads.ibge.gov.br/downloads_estatisticas.htm>. Acesso em: 16 jan. 2015.

INEP - Instituto Nacional de Estudos e Pesquisas Educacionais Anísio Teixeira. Sinopse Estatística do Ensino Superior: graduação 2003-2015. Brasília, 2003-2010; 2015. Disponível em: <http://portal.inep.gov.br/web/guest/sinopses-estatisticas-da-educacaosuperior>. Acesso em: 16 ago. 2016.

MANCEBO, Deise. Trabalho Docente na Educação Superior Brasileira: mercantilização das relações e heteronomia acadêmica. Revista Portuguesa de Educação, Braga, v. 23, n. 2, p. 73-91, 2010.

MANCEBO, Deise; MAUES, Olgaíses Cabral; CHAVES, Vera Lúcia. Crise e Reforma do Estado e da Universidade Brasileira: implicações para o trabalho docente. Educar, Curitiba, n. 28, p. 37-53, 2006.

MEROLA, Ediane. UERJ: prova de resistência em um mês de aula. O Globo, Rio de Janeiro, 10 maio 2017. Disponível em: <https://oglobo.globo.com/rio/uerj-prova-de-resistencia-em-ummes-de-aula-21317742>. Acesso em: 18 maio 2017.

PARÁ. Balanço Geral do Estado do Pará. Belém/PA: Secretaria de Estado da Fazenda, 2003-2010.

PROTTI, Alberto; LUQUE, Carlos; CRUZ, Hélio. Desafios do Financiamento das Universidades Estaduais Paulistas. Revista Gual, Florianópolis, v. 5, n. 4, p. 1-20, 2012.

SANTOS, Boaventura de Souza. A Universidade no Século XXI: para uma reforma democrática e emancipatória da universidade. São Paulo: Cortez, 2010.

SINDUEPA - Sindicato dos Docentes da UEPA; SINTAUEPA - Sindicato dos TécnicoAdministrativos da UEPA. Nota de Esclarecimento da Greve Geral dos Docentes e Técnico-Administrativos da Universidade do Estado do Pará. Belém/PA, 2005.

UEPA - Universidade do Estado do Pará. Relatório Acadêmico e Social de Gestão 2008/2009-2013. Belém/PA, 2014. 
O Financiamento das IEEs Brasileiras frente ao Processo de Expansão da Educação Superior

Giselle dos Santos Ribeiro é mestranda em Educação pelo Programa de Pós-Graduação em Educação da Universidade do Pará (UFPA), linha de políticas públicas educacionais. Especialista em Pedagogia da Cultura Corporal pela UEPA (2015). Licenciada em Educação Física pela UEPA (2013).

E-mail: giribeiroef@hotmail.com

Tayanne de Fátima Almeida Tabosa dos Reis é mestranda em Educação pelo Programa de Pós-Graduação em Educação da Universidade do Pará (UFPA), linha de políticas públicas educacionais. É graduada no curso de Licenciatura Plena em Pedagogia na Universidade Federal no Pará (UFPA).

E-mail: tayannetabosa@outlook.com

Valeria Silva de Moraes Novais é doutoranda em Educação pela Universidade Federal no Pará (UFPA), Mestre em Educação pela Universidade Federal do Pará e Graduada em Licenciatura Plena em Pedagogia pela Universidade Federal do Pará - UFPA. Atualmente é Professora Assistente da Universidade do Estado do Amapá (UEAP).

E-mail: valmoraes25@hotmail.com

Ana Paula Batista da Silva Brito é mestranda em Educação pelo Programa de Pós-Graduação em Educação da Universidade do Pará (UFPA), linha de políticas públicas educacionais. Graduada em Licenciatura Plena em Pedagogia, na Universidade Federal do Pará.

E-mail: anapaula.pbs@hotmail.com

Emerson Duarte Monte é doutor em Educação pela Universidade Federal do Pará. Mestre em Educação pela Universidade Federal do Pará. Tem experiência nas áreas de Educação Física, Políticas Públicas Educacionais e Educação Superior. Atual Coordenador do Curso de Especialização em Pedagogia da Cultura Corporal (UEPA).

E-mail: emersonmonte21@yahoo.com.br 


\section{Editores do volume 7}

José Marcelino de Rezende Pinto - Universidade de São Paulo, São Paulo/SP, Brasil

Nalú Farenzena - Universidade Federal do Rio Grande do Sul, Porto Alegre/RS, Brasil

\section{Comitê Editorial}

José Marcelino de Rezende Pinto - Universidade de São Paulo, Brasil

Juca Gil - Universidade Federal do Rio Grande do Sul, Brasil

Theresa Adrião - Universidade Estadual de Campinas, Brasil

Ângelo Ricardo de Souza - Universidade Federal do Paraná, Brasil

Márcia Aparecida Jacomini - Universidade Federal de São Paulo, Brasil

\section{Conselho Editorial}

\section{Alejandro Morduchowicz}

Universidad Pedagógica, Provincia de Buenos Aires, Argentina

Fernanda Saforcada

Universidade de Buenos Aires, Argentina

Jacques Velloso

Universidade de Brasília, Brasil

João Monlevade

Senado Federal, Brasil

Jorge Abrahão de Castro

Instituto de Pesquisa Econômica Aplicada / IPEA, Brasil

Juca Gil

Universidade Federal do Rio Grande do Sul, Brasil

Lisete Regina Gomes Arelaro

Universidade de São Paulo, Brasil

Luis Carlos Sales

Universidade Federal do Piauí, Brasil

Luiz de Sousa Junior

Universidade Federal da Paraíba, Brasil

Luiz Fernandes Dourado

Universidade Federal de Goiás, Brasil

Magna França

Universidade Federal do Rio Grande do Norte, Brasil

Maria Beatriz Luce

Universidade Federal do Pampa, Brasil

Universidade Federal do Rio Grande do Sul, Brasil

Marcos Edgar Bassi

Universidade Federal do Paraná, Brasil

Maria Dilnéia Espíndola Fernandes

Universidade Federal de Mato Grosso do Sul, Brasil

\section{Nalú Farenzena}

Universidade Federal do Rio Grande do Sul, Brasil

Nelson Cardoso do Amaral

Universidade Federal de Goiás, Brasil

Nicholas Davies

Universidade Federal Fluminense, Brasil

Rosana Evangelista Cruz

Universidade Federal do Piauí, Brasil

Rosana Gemaque

Universidade Federal do Pará, Brasil

Robert E. Verhine

Universidade Federal da Bahia, Brasil

Romualdo Portela de Oliveira

Universidade de São Paulo, Brasil

Theresa Adrião

Universidade Estadual de Campinas, Brasil

Tristan McCowan

University of London, Reino Unido

Vera Jacob

Universidade Federal do Pará, Brasil

Vera Peroni

Universidade Federal do Rio Grande do Sul, Brasil

Vitor Henrique Paro

Universidade de São Paulo, Brasil

\section{Equipe editorial}

Apoio ao Comitê Editorial: Patrícia Balthazar Garcia

Diagramação, Revisão de português e normalização: Edson Leonel de Oliveira

Revisão de inglês: Ananyr Porto Fajardo 